Article

\title{
Characterization of a G-Quadruplex Structure in Pre-miRNA-1229 and in Its Alzheimer's Disease-Associated Variant rs2291418: Implications for miRNA-1229 Maturation
}

\author{
Joshua A. Imperatore, McKenna L. Then, Keefe B. McDougal and Mihaela Rita Mihailescu * \\ Department of Chemistry and Biochemistry, Duquesne University, Pittsburgh, PA 15282, USA; \\ imperat1@duq.edu (J.A.I.); thenm@duq.edu (M.L.T.); mcdougal.28@buckeyemail.osu.edu (K.B.M.) \\ * Correspondence: mihailescum@duq.edu
}

Received: 23 December 2019; Accepted: 20 January 2020; Published: 24 January 2020

\begin{abstract}
Alzheimer's disease (AD), the most common age-related neurodegenerative disease, is associated with various forms of cognitive and functional impairment that worsen with disease progression. $\mathrm{AD}$ is typically characterized as a protein misfolding disease, in which abnormal plaques form due to accumulation of tau and $\beta$-amyloid $(\mathrm{A} \beta)$ proteins. An assortment of proteins is responsible for the processing and trafficking of $A \beta$, including sortilin-related receptor 1 (SORL1). Recently, a genome-wide association study of microRNA-related variants found that a single nucleotide polymorphism (SNP) rs2291418 within premature microRNA-1229 (pre-miRNA-1229) is significantly associated with AD. Moreover, the levels of the mature miRNA-1229-3p, which has been shown to regulate the SORL1 translation, are increased in the rs2291418 pre-miRNA-1229 variant. In this study we used various biophysical techniques to show that pre-miRNA-1229 forms a G-quadruplex secondary structure that coexists in equilibrium with the canonical hairpin structure, potentially controlling the production of the mature miR-1229-3p, and furthermore, that the AD-associated SNP rs2291418 pre-miR-1229 changes the equilibrium between these structures. Thus, the G-quadruplex structure we identified within pre-miRNA-1229 could potentially act as a novel therapeutic target in $\mathrm{AD}$.
\end{abstract}

Keywords: RNA G-quadruplex; pre-miRNA-1229; Alzheimer's disease; rs2291418

\section{Introduction}

Alzheimer's disease (AD) is the most common age-related neurodegenerative disease, currently affecting an estimated 4.7 million people in the United States alone, with that number expected to nearly triple to a projected 13.8 million by the year 2050 [1]. The disease is characterized by cognitive declines such as progressive memory loss, confusion, and disorientation, as well as behavioral and mood changes [2]. It is widely accepted that $\mathrm{AD}$ is also a leading cause of dementia in older individuals [3,4]. At a molecular level, the development of $\mathrm{AD}$ can be associated with the accumulation of filamentous tau tangles inside of neurons and of beta amyloid $(\mathrm{A} \beta)$ plaques extracellularly. The accumulation of these proteins interferes with proper neuron-to-neuron communication at synapses in $\mathrm{AD}$, resulting in disrupted communication of information and eventual cell death [5].

$\mathrm{A} \beta$ is generated by endoproteolytic cleavage into a 40-42 amino acid fragment from the transmembrane amyloid precursor protein (APP) [6,7]. While the main function of APP has not yet been determined, it is generally agreed upon that dysregulation of its processing is a major factor in the development of the neurotoxic $A \beta$ deposits in $\mathrm{AD}$ [8]. Many studies have determined that this may occur due to missense mutations within APP, resulting in an increased production of $A \beta_{42}$, 
the longer and more amyloidogenic variant that has an increased prevalence in $\mathrm{AD}$ patients $[9,10]$. However, another possibility is that the dysregulation of various other proteins involved in this process may impair proper cleavage and trafficking of APP. Genome-wide association (GWAS) studies have determined a comprehensive list of genes associated with $A D$, including those that encode for apolipoprotein E (APOE) [11], death-associated protein kinase 1 (DAPK1) [12], interleukin 8 (IL8) [13], transferrin [14], and sortilin-related receptor (SORL1) [15]. The latter of these proteins, SORL1, is a multifunctional membrane-bound receptor protein expressed throughout the brain that plays roles in cell-to-cell signaling and vesicle trafficking $[16,17]$. Recent studies have reported that SORL1 functions to direct APP into recycling pathways under normal conditions. However, the downregulation of SORL1 expression results in APP being sorted into A $\beta$-generating pathways, demonstrating a potential mechanistic function of SORL1 in AD pathogenesis [18]. Inherited genetic variants within SORL1 mRNA that are associated with AD have been shown to downregulate SORL1 protein translation [18].

Additionally, other molecular mechanisms, such as microRNA (miRNA) dysregulation, have also been proposed to be involved in AD pathogenesis $[19,20]$. miRNAs are a class of short, noncoding RNAs approximately 20-24-nucleotides (nt) in length which bind to complementary "seed regions" within the $3^{\prime}$ untranslated region (UTR) of mRNAs and regulate their translation [21]. The mature miRNAs are produced via a distinct biogenesis pathway, which begins with the transcription of miRNA genes to produce the primary miRNA (pri-miRNA), which is further processed by the ribonuclease III enzyme Drosha and the protein DiGeorge syndrome critical region 8 (DGCR8) into precursor miRNAs (pre-miRNAs), 70-90-nt sequences that contain a 2-nt overhang on their $3^{\prime}$ end [22-24]. The pre-miRNAs, proposed to fold into extended hairpin structures, are exported to the cytoplasm in a Ran-GTP energy-driven process by the nucleocytoplasmic shuttling protein Exportin-5, which recognizes their $3^{\prime}$ overhang [25]. In the cytoplasm, the endoribonuclease III enzyme Dicer recognizes the pre-miRNA stem-loop structure, cleaving off the terminal loop and yielding an imperfect double-stranded miRNA:miRNA* duplex [26,27]. Dicer further associates with various other proteins to form the RNA-induced silencing complex (RISC), including Argonaute2 (AGO2) and human immunodeficiency virus (HIV) transactivating response RNA (TAR) binding protein (TRBP) [28,29]. While the mature miRNA remains incorporated in the miRNA:RISC complex, the opposite strand, or passenger strand (miRNA*), is discarded [30]. The miRNA-guided RISC complex subsequently recognizes and binds to mRNA targets, leading to mRNA cleavage and/or translational repression.

The importance of regulating miRNA levels has been demonstrated in a multitude of studies, with dysregulated levels being associated with various diseases, such as AD [31], Down syndrome [32], and many cancers [33]. It has been proposed that the formation of alternative secondary structures in pre-miRNAs can affect their processing by Dicer and thus, the mature miRNA production within the cell $[34,35]$. Bioinformatic studies have concluded that $13-16 \%$ of all human pre-miRNA sequences contain guanine-rich (G-rich) regions that have the potential to form G-quadruplex (GQ) structures [34,35]. GQs are non-canonical secondary structures formed by stacking of two or more cyclic, planar G-quartet arrangements of four guanine residues and stabilized by Hoogsteen-type hydrogen bonds, $\pi-\pi$ stacking interactions, and intercalating monovalent cations $[36,37]$. The formation of these GQ structures within G-rich pre-miRNAs has been proposed to inhibit their processing by Dicer due to the lack of a terminal stem loop. Among the pre-miRNAs with G-rich sequences which have the potential to form GQ structures is pre-miRNA-1229, whose mature miRNA product, miRNA-1229-3p, has recently been shown to directly control the expression of SORL1 [38]. Moreover, Ghanbari et al. performed a GWAS which demonstrated that the allelic guanine to adenine rs2291418 variant (cytosine to uracil in the RNA) within pre-miRNA-1229 is associated with AD and that this single nucleotide polymorphism (SNP) enhances the production of miRNA-1229-3p and decreases the levels of SORL1 [38].

In this study, we utilized various biophysical techniques to show that a GQ structure forms in pre-miRNA-1229 which coexists in equilibrium with the canonical extended hairpin structure and that this equilibrium is shifted in the rs2291418 variant, favoring the extended hairpin structure. 
These results suggest a mechanism leading to the increased production of the mature miRNA-1229-3p in AD and raise the possibility of using the GQ structure within pre-miRNA-1229 as a potential therapeutic target in $\mathrm{AD}$ [39].

\section{Results}

\subsection{The G-Rich Region of Pre-miRNA-1229 Folds into a GQ Structure}

The formation of GQ structures in pre-miRNA sequences has been proposed to alter the efficiency of miRNA production [34,35]. Since pre-miRNA-1229 has multiple G-tracts, numbered 1 to 6 in Figure 1A), we used the online QGRS Mapper (http://bioinformatics.ramapo.edu/ QGRS/analyze.php) software, which predicted that a three-plane GQ structure can form in this pre-miRNA using the G-tracts 2, 3, 4, and 5 (Figure 1A,C). To determine if this G-rich region of pre-miRNA-1229 indeed folds into the predicted GQ structure, we initially investigated a truncated sequence spanning nucleotides 1-42 of pre-miRNA-1229 that contains the six G-tracts that could participate in GQ structure formation (named pre-miRNA-1229_WT GQ, Table 1).

$\mathbf{A}$

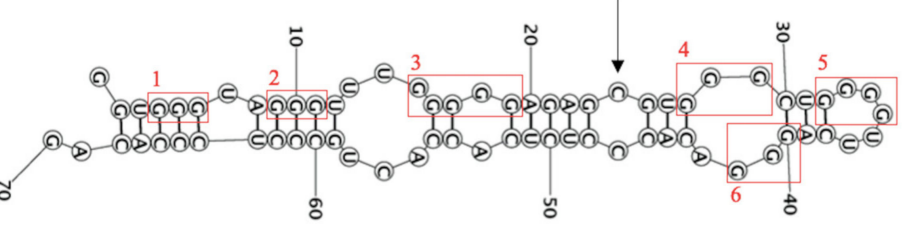

B

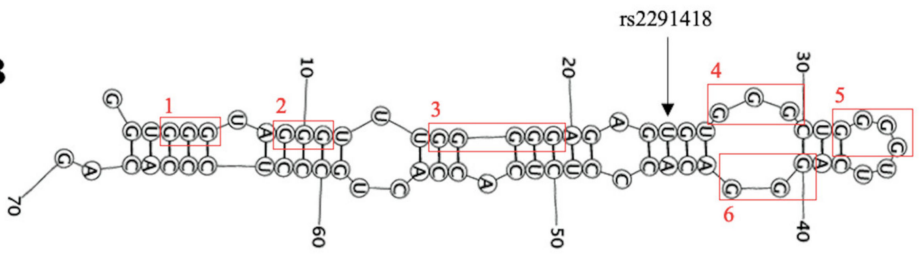

C

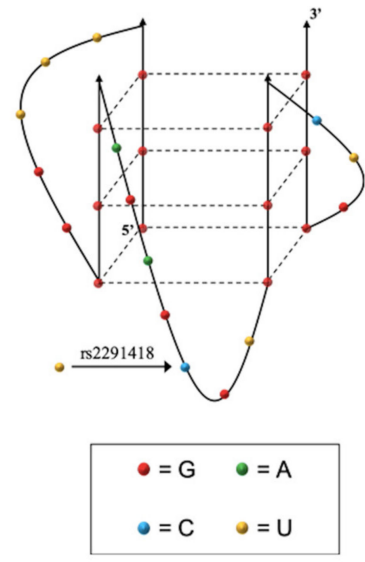

Figure 1. Predicted secondary structures of pre-miRNA-1229 sequences. RNA Structure prediction software (https://rna.urmc.rochester.edu/RNAstructureWeb/) was used to determine the most likely hairpin structures for full-length pre-miRNA-1229_WT (A) and pre-miRNA-1229_SNP (B). G-tracts are numbered and highlighted by red boxes. The location of the SNP is indicated with an arrow in both structures. The predicted GQ structure of full-length pre-miRNA-1229 was determined using the online QGRS Mapper software (C). Nucleotides involved in GQ formation are colored according to the legend below and the location of SNP is indicated with an arrow.

Table 1. RNA sequences used in this study. G-rich areas within pre-miRNA sequences with potential to form G-quadruplex structures are underlined. The SNP mutation locations are highlighted in bold and italic.

\begin{tabular}{cl}
\hline pre-miRNA-1229_WT GQ & $\begin{array}{l}5^{\prime} \text { GGGUAGGGUUUGGGGGAGAGCGUGGGCUGGGGUUCAGGG } \\
\text { ACA } 3^{\prime}\end{array}$ \\
\hline \multirow{2}{*}{ pre-miRNA-1229_WT FL } & $\begin{array}{l}5^{\prime} \text { GGUGGGUAGGGUUUGGGGGAGAGCGUGGGCUGGGG } \\
\text { UUCAGGGACACCCUCUCACCACUGCCUCCCACAG 3' }\end{array}$ \\
\hline \multirow{2}{*}{ pre-miRNA-1229_SNP GQ } & $\begin{array}{l}5^{\prime} \text { GGGUAGGGUUUGGGGGAGAGUGUGGGCUGGGGUUCAGGG } \\
\text { ACA } 3^{\prime}\end{array}$ \\
\hline \multirow{2}{*}{ pre-miRNA-1229_SNP FL } & $\begin{array}{l}5^{\prime} \text { GGUGGGUAGGGUUUGGGGGAGAGUGUGGGCUGGGG } \\
\text { UUCAGGGACACCCUCUCACCACUGCCCUCCCACAG 3' }\end{array}$ \\
\hline
\end{tabular}

We first characterized pre-miRNA-1229_WT GQ RNA using 1D ${ }^{1} \mathrm{H}$ NMR spectroscopy focusing on the imino proton resonance region between 10 and $15 \mathrm{ppm}$ and titrating increasing $\mathrm{KCl}$ concentrations in the range of $0-150 \mathrm{mM}$, as $\mathrm{K}^{+}$ions stabilize GQ structures (Figure 2A) [36]. Broad resonances are 
apparent even at $0 \mathrm{mM} \mathrm{KCl}$ in the 10-12 ppm region corresponding to guanine imino protons involved in Hoogsteen base pairs in GQ structures [40]. Another resonance is also evident around 13.3 ppm, within the imino proton region 12-14.5 ppm assigned to imino protons involved in Watson-Crick base pairs (Figure 2A, bottom spectrum) [40]. We hypothesize that this resonance arises from Watson-Crick loop-loop interactions within the GQ structure. Increasing $\mathrm{KCl}$ concentrations do not seem to have an effect on the intensity of the resonances in the GQ region (Figure 2A), indicating that a GQ structure is stably formed even in the absence of $\mathrm{K}^{+}$. RNA sequences have been shown to form stable GQ structures even in the absence of $\mathrm{K}^{+}$ions, while these ions are required for GQ formation in DNA of identical sequence [41].

A

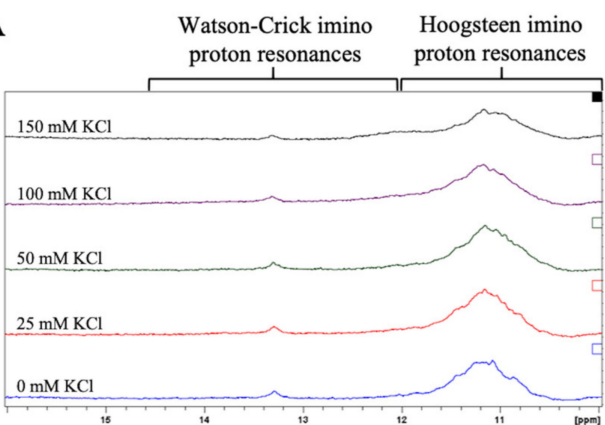

$\mathbf{C}$

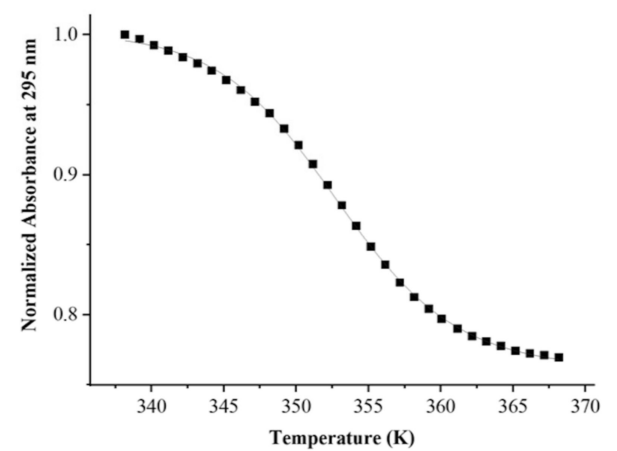

$\mathbf{E}$

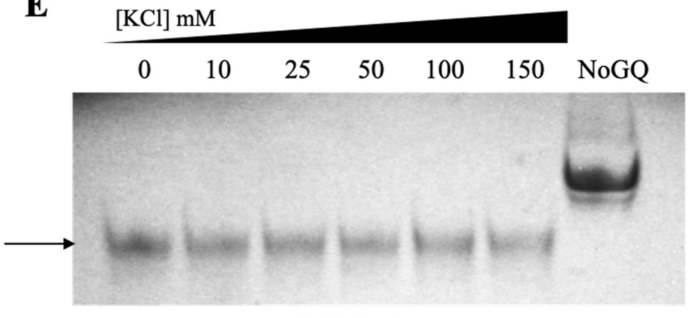

UV Shadow
B

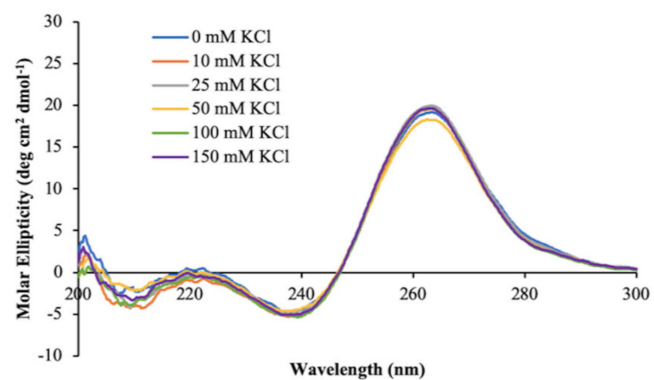

D
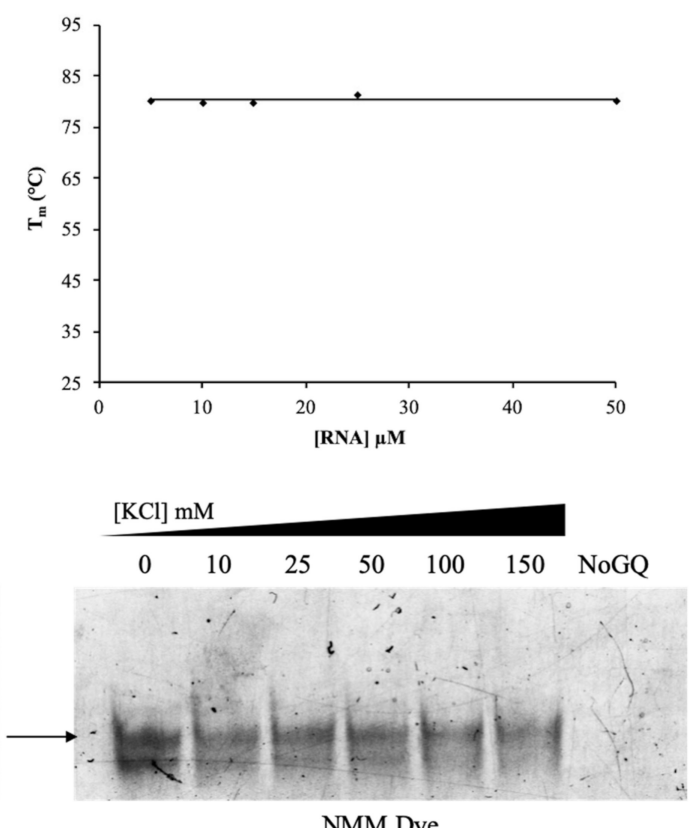

Figure 2. Biophysical characterization of the truncated pre-miRNA-1229_WT GQ sequence. ${ }^{1} \mathrm{H}$ NMR spectra (A) and CD spectra (B) at various $\mathrm{KCl}$ concentrations in $10 \mathrm{mM}$ cacodylic acid, $\mathrm{pH}$ 6.5, demonstrating the formation of a GQ structure. The UV thermal denaturation hypochromic transition (C) at $10 \mu \mathrm{M}$ RNA in $150 \mathrm{mM} \mathrm{KCl}$ was fit using Equation (1) (Materials and Methods), to determine a $\mathrm{T}_{\mathrm{m}}$ of $\sim 80{ }^{\circ} \mathrm{C}$. The $\mathrm{T}_{\mathrm{m}}$ values plotted as a function of the RNA concentration (D) revealed that an intramolecular GQ structure is formed. Nondenaturing gel electrophoresis (E) visualized by UV shadow (left panel) and stained with the GQ-specific $N$-methyl mesoporphyrin IX (NMM) dye (right panel), revealing the formation of a $\mathrm{GQ}$ structure at all $\mathrm{KCl}$ concentrations.

While both parallel and anti-parallel GQ structures have been observed in DNA, RNA GQs typically only adopt a parallel directionality [42]. To determine the directionality of the GQ structure in pre-miRNA-1229_WT GQ, we performed circular dichroism (CD) spectroscopy experiments. 
Parallel GQ structures show a positive band at $\sim 265 \mathrm{~nm}$ and a negative band at $\sim 240 \mathrm{~nm}$, whereas the signatures of an antiparallel GQ are a positive band at $\sim 295 \mathrm{~nm}$ and a negative band at $\sim 260 \mathrm{~nm}$ [42]. Our experiments confirm that a parallel GQ forms within pre-miRNA-1229_WT GQ, as we observed a positive band at $\sim 265 \mathrm{~nm}$ and a negative one at $\sim 240 \mathrm{~nm}$. Moreover, the intensity of these bands changes minimally as the $\mathrm{KCl}$ concentration is increased (Figure 2B), consistent with the ${ }^{1} \mathrm{H} \mathrm{NMR}$ spectroscopy results (Figure 2A), indicating that the GQ structure formed by pre-miRNA-1229_WT GQ is stable even in the absence of $\mathrm{K}^{+}$ions. Helical structures in A-RNA give rise to a positive band at $260 \mathrm{~nm}$, a negative band at $210 \mathrm{~nm}$, and a small negative CD between 290 and $300 \mathrm{~nm}$ [43]. We observed a low intensity negative band at $\sim 210 \mathrm{~nm}$, however, since the intensity of this band is too low with respect to that of the positive band at $260 \mathrm{~nm}$ and we did not observe the small negative CD between 290 and $300 \mathrm{~nm}$, we rule out the formation of a hairpin structure in pre-miRNA-1229_WT GQ [43]. Similar to the ${ }^{1} \mathrm{H}$ NMR spectroscopy single resonance at $13.3 \mathrm{ppm}$, we assign the origin of the $210 \mathrm{~nm}$ small intensity band to Watson-Crick loop-loop interactions within the GQ structure.

To determine the overall stability of the GQ structure formed in pre-miRNA-1229_WT GQ, we performed UV thermal denaturation experiments at $295 \mathrm{~nm}$, wavelength sensitive to GQ structure dissociation, at a fixed $\mathrm{KCl}$ concentration of $150 \mathrm{mM}$ and a range of RNA concentrations from 5 to $50 \mu \mathrm{M}$ (Supplemental Figure S1A) [44]. At all RNA concentrations investigated, a single hypochromic transition corresponding to the unfolding of a GQ structure was observed (Supplemental Figure S1A). The melting temperature $\left(\mathrm{T}_{\mathrm{m}}\right)$ of the GQ structure at each RNA concentration was determined by fitting this hypochromic transition with Equation (1) (Materials and Methods) (Figure 2C) [45] to be $\sim 80^{\circ} \mathrm{C}$ at all RNA concentrations investigated (Figure 2D), indicating that pre-miRNA-1229_WT GQ forms an intramolecular GQ structure [46].

Finally, we analyzed pre-miRNA-1229_WT GQ by $20 \%$ nondenaturing polyacrylamide gel electrophoresis at various $\mathrm{KCl}$ concentrations in the range of $0-150 \mathrm{mM}$ (Figure 2E, full gel shown in Supplemental Figure S1B). A main band was observed at each $\mathrm{KCl}$ concentration when the gel was visualized by UV shadowing (Figure 2E, left panel) [47]. This band stained in $N$-methyl mesoporphyrin IX (NMM), a GQ-specific dye (Figure 2E, right panel), revealing that it corresponds to a GQ structure [48]. Additionally, a lower band became clearly visible in the NMM stained gel, indicating the formation of an alternate GQ structure. While Figure 1C depicts the most stable GQ structure predicted by the QGRS Mapper software, multiple GQ structures could be formed in pre-miRNA-1229_WT GQ because it contains six G-tracts and only four of these are required for the formation of a GQ structure [34,35]. A negative control RNA that cannot form a GQ structure (NoGQ) was visible when the gel was visualized by UV shadowing (Figure 2E, left panel), but absent when stained with NMM (Figure 2E, right panel) [47].

Taken together, the results from these biophysical studies confirm the formation of a parallel, intramolecular GQ structure with a $\mathrm{T}_{\mathrm{m}}$ of $\sim 80^{\circ} \mathrm{C}$ in $150 \mathrm{mM} \mathrm{KCl}$ in the truncated pre-miRNA-1229_WT GQ sequence.

\subsection{Full-Length Pre-miRNA-1229 Forms a GQ Structure That Coexists in Equilibrium with an Extended Hairpin Structure}

Next we investigated if the GQ structure formed by the G-rich region of pre-miR-1229 is retained within the full-length pre-miRNA-1229_WT sequence (pre-miRNA-1229_WT FL, Table 1), where additional nucleotides past position 42 compete for the formation of the canonical extended hairpin structure. $1 \mathrm{D}^{1} \mathrm{H}$ NMR spectroscopy experiments were performed to monitor secondary structure formation by observing the imino proton resonance region while titrating increasing $\mathrm{KCl}$ concentrations (Figure 3A). Multiple resonances between 12 and $14.5 \mathrm{ppm}$, which indicate the formation of a hairpin structure, were observed for pre-miRNA-1229_WT FL, these resonances being absent in pre-miRNA-1229_WT GQ (compare Figures 2A and 3A) [40]. The broadness of these resonances could be due to the size of the RNA investigated, but it could also indicate possible exchange between different conformations. Sharper resonances on a broad envelope background were also observed in the range of 10-12 ppm. As discussed above, resonances in the range of 10-12 ppm are assigned to 
guanine imino protons involved in Hoogsteen base pairs in GQ structures [40]. However, in sequences that cannot form GQ structures, sharper resonances in these regions were assigned to GU wobble base pairs or side-by-side GG/GA base pairs, while broader resonances were assigned to unpaired G or $\mathrm{U}$ imino protons located in hairpin loops $[49,50]$. Moreover, although Watson-Crick imino protons are observed typically in the range of $12-14.5 \mathrm{ppm}$, there are instances where the imino proton of a guanine involved in a GC base pair immediate to an internal loop could give rise to a resonance around 11.9 ppm [49]. The predicted extended hairpin structure of pre-miRNA-1229_WT FL (Figure 1A) contains internal loops where GG or GA base pairs could form, unpaired G and U residues in the terminal loop, as well as GC Watson-Crick base pairs immediately adjacent to internal loops, all of which could give rise to the sharper resonances observed in the 10-12 ppm region. The presence of a broader envelope resonance centered around $11 \mathrm{ppm}$, visible especially upon addition of higher $\mathrm{KCl}$ concentrations, suggests also the presence of a GQ structure (Figure 3A). However, the GQ structure signatures become clearly visible only once the sample is annealed in the presence of $150 \mathrm{mM} \mathrm{KCl}$, as the intensity of the broad resonance around $11 \mathrm{ppm}$ increases with the concomitant decrease of the resonances in the Watson-Crick imino proton region (Figure 3A, top spectrum). These results indicate that pre-miRNA-1229_WT FL forms a GQ structure coexisting in equilibrium with a hairpin structure, with the GQ structure being stabilized by annealing the RNA in the presence of $\mathrm{KCl}$.
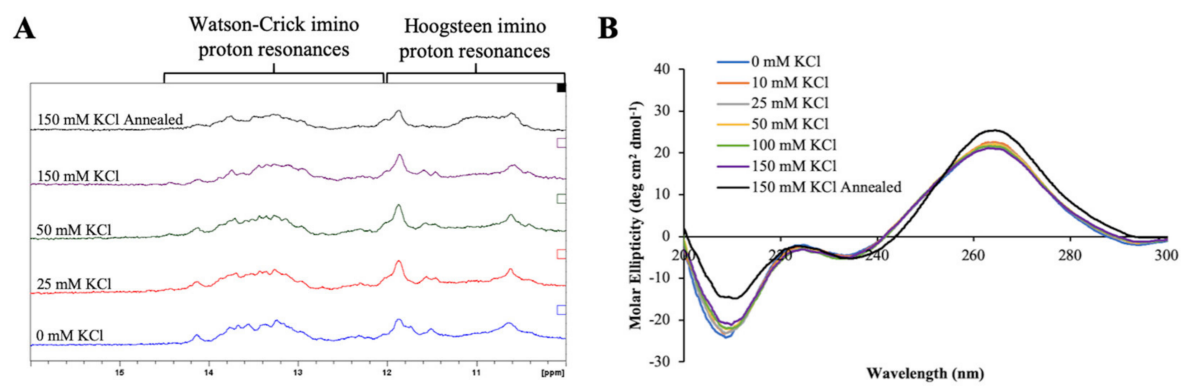

C
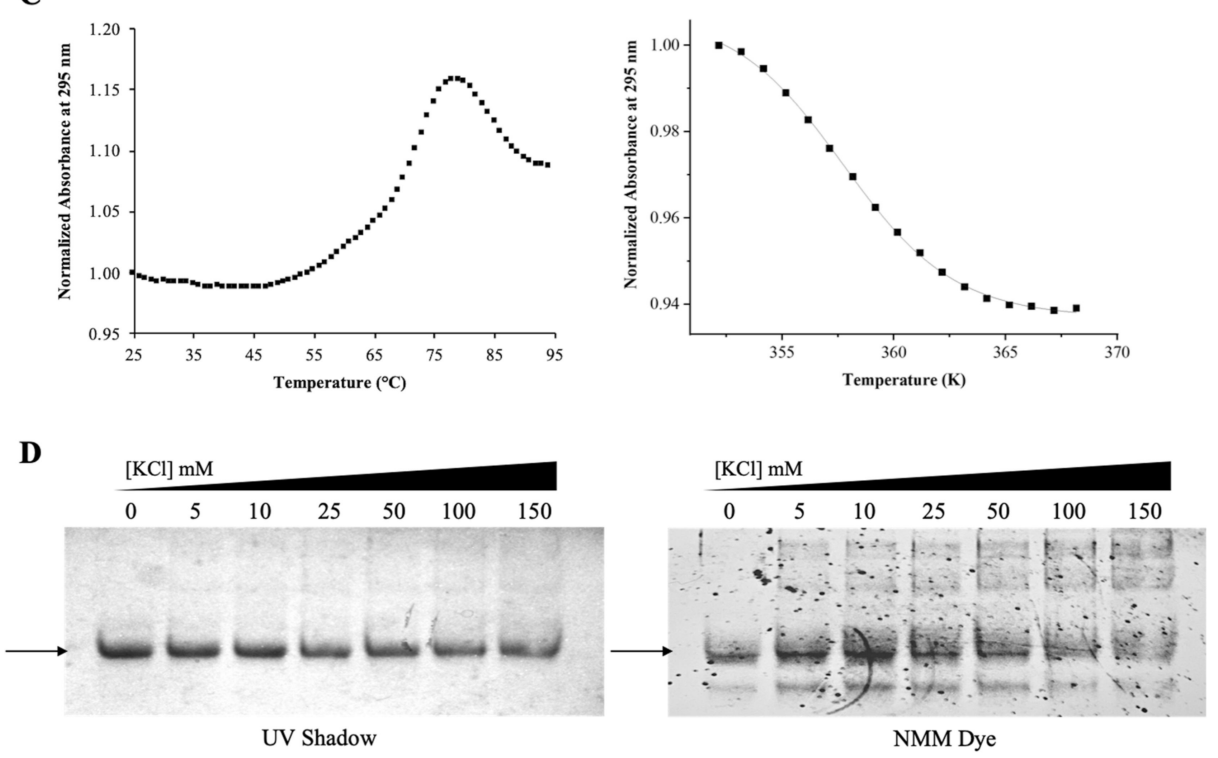

Figure 3. Biophysical characterization of the full-length pre-miRNA-1229_WT FL sequence. ${ }^{1} \mathrm{H}$ NMR spectra (A) and CD spectra (B) at various $\mathrm{KCl}$ concentrations in $10 \mathrm{mM}$ cacodylic acid, $\mathrm{pH}$ 6.5, reveal an equilibrium between hairpin and GQ structures after annealing the RNA in $150 \mathrm{mM} \mathrm{KCl}$. The UV thermal denaturation hypochromic transition (C) at $10 \mu \mathrm{M}$ RNA in $100 \mathrm{mM} \mathrm{KCl}$ was fit using Equation (1) (Materials and Methods), to determine a $\mathrm{T}_{\mathrm{m}}$ of $\sim 85^{\circ} \mathrm{C}$. Nondenaturing gel electrophoresis (D) visualized by UV shadow (left panel) and stained with the GQ-specific NMM dye, revealing the formation of multiple GQ structures. 
CD spectroscopy experiments were performed next for pre-miRNA-1229_WT FL at varying KCl concentrations in the range of $0-150 \mathrm{mM}$ (Figure 3B), revealing a positive band at $\sim 265 \mathrm{~nm}$, a negative band at $\sim 235 \mathrm{~nm}$, an intense negative band at $210 \mathrm{~nm}$, and a small negative CD between 290 and $300 \mathrm{~nm}$. These bands, which did not change significantly with the $\mathrm{KCl}$ titrations, are consistent with the presence of both a hairpin and a GQ structure coexisting in equilibrium [42,43]. Additionally, consistent with ${ }^{1} \mathrm{H}$ NMR spectroscopy results (Figure $3 \mathrm{~A}$, top spectrum), only when the sample was annealed at $95^{\circ} \mathrm{C}$ in $150 \mathrm{mM} \mathrm{KCl}$ was a noticeable difference observed in the $\mathrm{CD}$ spectrum, with an increase in the intensity of the positive band at $\sim 265 \mathrm{~nm}$ and a decrease in the intensity of the negative band at $\sim 210 \mathrm{~nm}$, indicating a shift of the equilibrium towards the GQ structure.

UV thermal denaturation experiments were performed at $295 \mathrm{~nm}$ to determine the stability of the GQ structure formed within the pre-miRNA-1229_WT FL sequence [44]. A hypochromic transition corresponding to GQ structure dissociation was observed between 79 and $95^{\circ} \mathrm{C}$, and a hyperchromic transition was observed between 46 and $79^{\circ} \mathrm{C}$, corresponding to the hairpin structure dissociation (Figure 3C). These experiments were performed in the presence of $100 \mathrm{mM} \mathrm{KCl}$, as at $150 \mathrm{mM} \mathrm{KCl}$, the GQ structure was too stable, resulting in an incomplete hypochromic transition (data not shown). The GQ dissociation transition was fit using Equation (1) (Materials and Methods) (Figure 3C) to determine a $\mathrm{T}_{\mathrm{m}}$ of $\sim 85^{\circ} \mathrm{C}[45]$.

To further characterize the equilibrium between the hairpin and GQ structures in pre-miRNA-1229_WT FL, we performed 15\% nondenaturing gel electrophoresis at various concentrations of $\mathrm{KCl}$ (Figure 3D). When the gel was visualized by UV shadowing, a single main band was evident at all concentrations of $\mathrm{KCl}$, with very faint upper bands also apparent (Figure 3D, left panel) [47]. When the gel was stained in the GQ-specific NMM dye, the main band stained, but multiple upper bands and a lower band also became clearly visible (Figure 3D, right panel), indicating the presence of multiple GQ structure conformations due to the presence of six G-tracts in the sequence (Figure 1A), as well as possible stacking interactions between GQ structures [48].

The results from these biophysical characterization studies show that GQ structures are retained in the context of the full-length pre-miRNA-1229_WT FL sequence, which coexist in equilibrium with the canonical extended hairpin structure. Additionally, while the GQ structure can form in the absence of $\mathrm{K}^{+}$ions, it is stabilized by annealing the RNA in the presence of $150 \mathrm{mM} \mathrm{KCl}$ (Figure 3A).

To monitor the equilibrium between the GQ and hairpin structures in ionic conditions closer to physiological conditions, $1 \mathrm{mM} \mathrm{MgCl} 2$ was added to the NMR sample previously annealed in the presence of $150 \mathrm{mM} \mathrm{KCl}$ (Figure $4 \mathrm{~A}$, bottom spectrum), acquiring time-dependent spectra over the course of 6 days, during which time the sample was incubated at $37^{\circ} \mathrm{C}$ (Figure 4). $\mathrm{Mg}^{2+}$ ions stabilize various RNA structures, including hairpins, and this was observed for pre-miRNA-1229_WT FL since the imino proton resonances corresponding to Watson-Crick base pairs become sharper over time (Figure 4A) [40,51]. However, it is interesting to note that the broad resonances centered around $11 \mathrm{ppm}$, corresponding to guanine imino protons engaged in Hoogsteen base pairs in the GQ structure, increase in intensity, suggesting that the equilibrium is shifted towards the GQ structure over time (Figure 4A and overlay of spectra in Figure 4B).

Taken together, these studies show for the first time that a GQ structure coexists in equilibrium with a hairpin structure within the G-rich pre-miRNA-1229 sequence. GQ structure formation within pre-miRNAs has been previously shown to reduce the levels of mature miRNA production [34,35], thus, our results suggest that the GQ structure within pre-miRNA-1229 could provide a fine-tuning control mechanism for the production of mature miRNA-1229. The results of this study have implications for $\mathrm{AD}$, as the mature miRNA-1229 has been shown to regulate the translation of SORL1, a protein whose downregulated expression has been shown to result in APP being sorted into A $\beta$-generating pathways $[18,38]$. Thus, the GQ structure we characterized within pre-miRNA-1229 could potentially become a therapeutic target in $\mathrm{AD}$, as molecules that stabilize it could ultimately reduce the levels of mature miRNA-1229 [39]. 

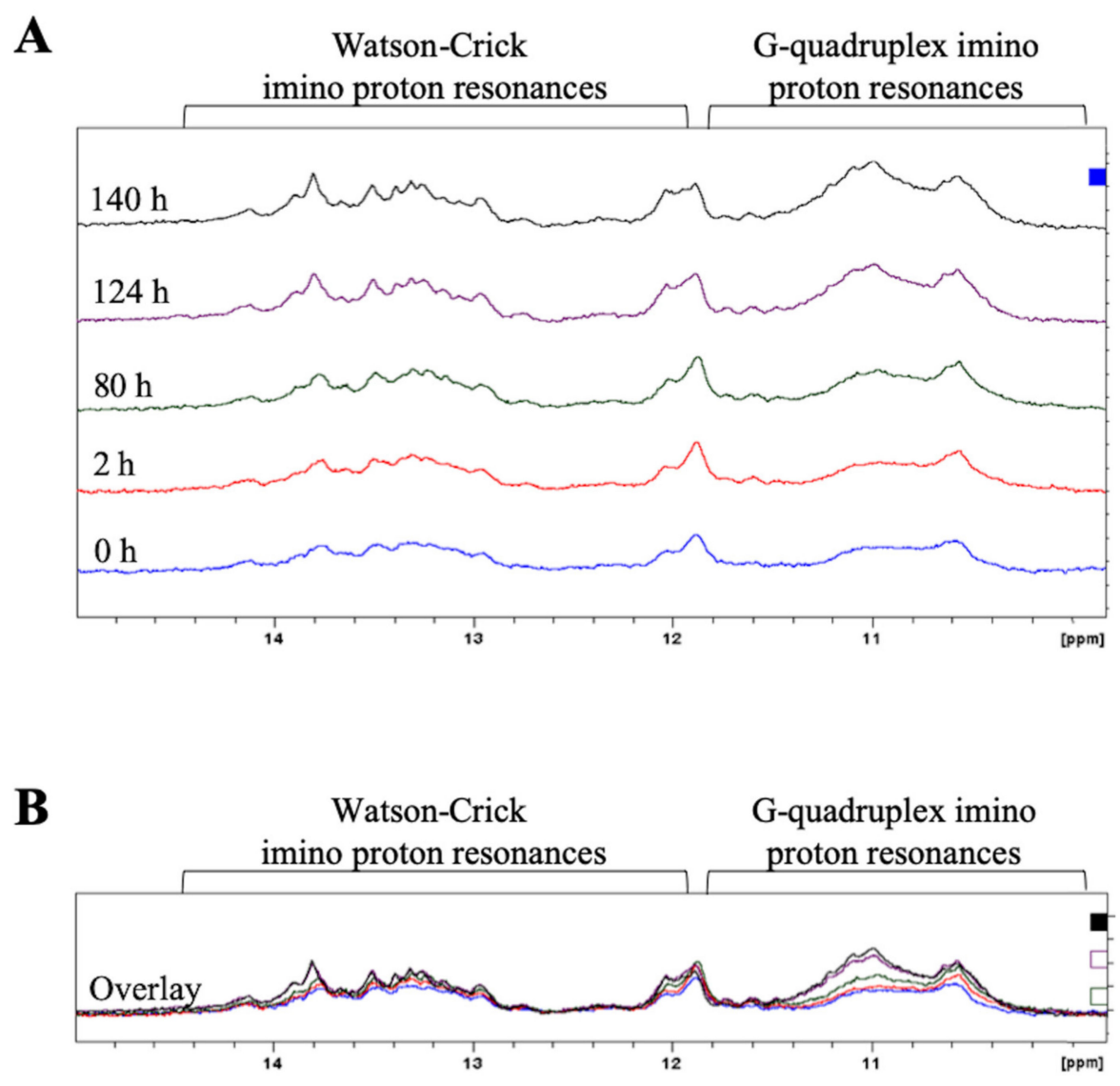

Figure 4. Time-dependent ${ }^{1} \mathrm{H}$ NMR spectra of full-length pre-miR-1229_WT FL in the presence of $150 \mathrm{mM} \mathrm{KCl}$ and $1 \mathrm{mM} \mathrm{MgCl}_{2}$ (A). After approximately $140 \mathrm{~h}$, the GQ structure is the preferred structure, as indicated by the increased intensity of the imino proton resonances corresponding to Hoogsteen base pairs in the GQ structure compared to those assigned to Watson-Crick imino proton resonances. An overlay of the spectra is shown in (B).

2.3. The GQ Structure Formed by the G-Rich Region of Pre-miRNA-1229 Is Retained in the AD-Associated rs2291418 Variant

Ghanbari et al. demonstrated not only that miRNA-1229 is implicated in AD by regulating the translation of SORL1, but also that the pre-miRNA-1229 variant rs2291418 (cytosine to uracil in the RNA, indicated by arrows in Figure 1), which results in increased levels of mature miRNA-1229-3p, is associated with AD [38]. Given that the rs2291418 SNP is located within the G-rich region of pre-miRNA-1229 (arrows in Figure 1A-C), we hypothesized that this variant could potentially change the equilibrium between the GQ and hairpin structures within pre-miRNA-1229 and consequently dysregulate the control of the mature miRNA-1229 production. Similar to our initial investigation of the truncated 42-nt pre-miRNA-1229_WT GQ, we generated a truncated pre-miRNA-1229_SNP sequence (named pre-miRNA-1229_SNP GQ, Table 1) and characterized it by using similar biophysical techniques. ${ }^{1} \mathrm{H}$ NMR spectroscopy experiments of pre-miRNA-1229_SNP GQ revealed broad imino proton resonances centered around $11 \mathrm{ppm}$ which increased in intensity as $\mathrm{KCl}$ was titrated in the sample (Figure 5A), indicative of the formation of a GQ structure that is stabilized by $\mathrm{K}^{+}$ions [40]. Interestingly, no resonances were observed in the region corresponding to Watson-Crick imino protons as was observed for the truncated WT sequence (compare Figures 2A and 5A), suggesting that the rs2291418 SNP disrupts the loop-loop interactions that were occurring within the wild-type sequence. 


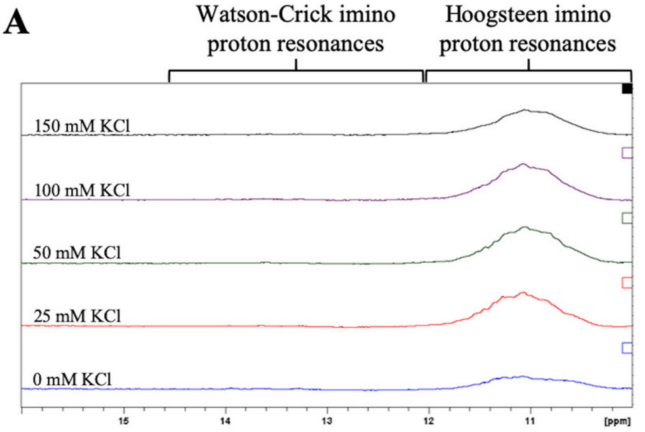

C

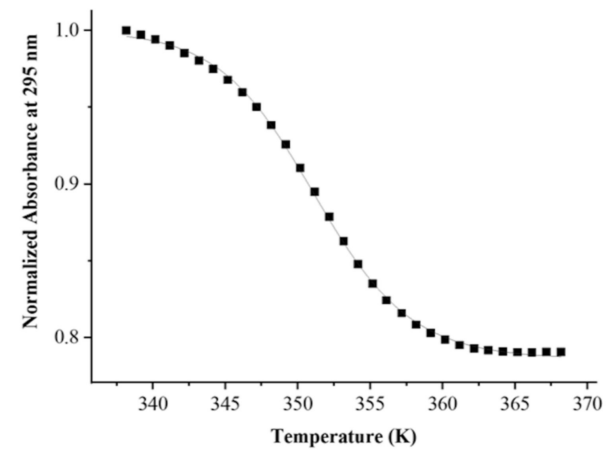

$\mathbf{E}$

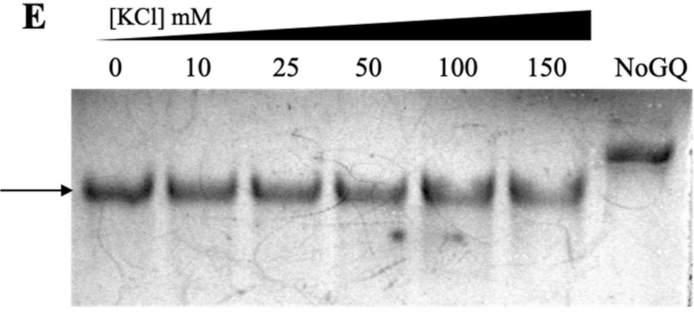

UV Shadow

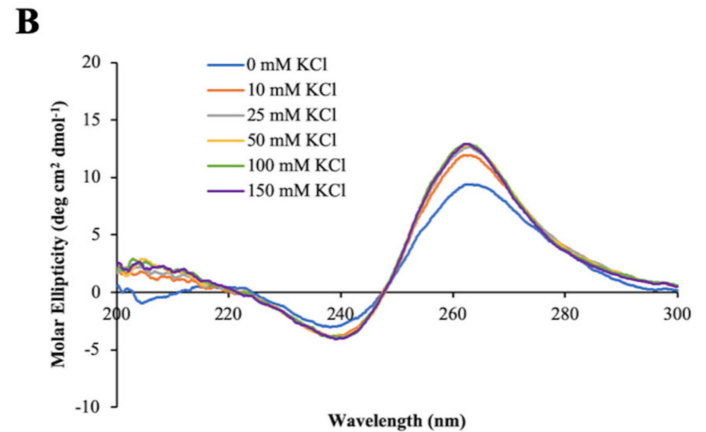

D

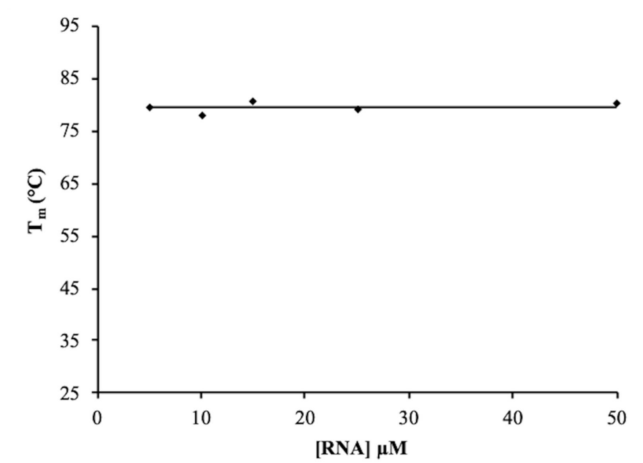
$[\mathrm{KCl}] \mathrm{mM}$

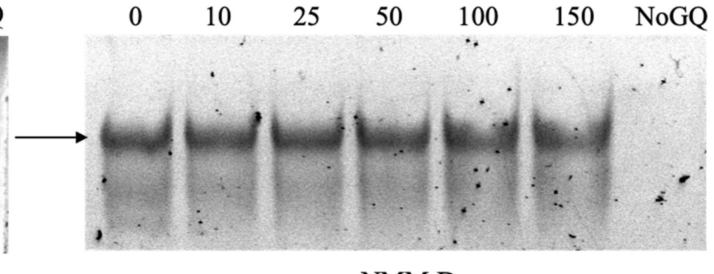

Figure 5. Biophysical characterization of the truncated pre-miR-1229_SNP GQ sequence. ${ }^{1} \mathrm{H}$ NMR spectra (A) and CD spectra (B) at various $\mathrm{KCl}$ concentrations in $10 \mathrm{mM}$ cacodylic acid, $\mathrm{pH}$ 6.5, demonstrating the formation of a GQ structure. The UV thermal denaturation hypochromic transition (C) at $10 \mu \mathrm{M}$ RNA in $150 \mathrm{mM} \mathrm{KCl}$ was fit using Equation (1) (Materials and Methods), to determine a $\mathrm{T}_{\mathrm{m}}$ of $\sim 78{ }^{\circ} \mathrm{C}$. The $\mathrm{T}_{\mathrm{m}}$ values plotted as a function of the RNA concentration (D) revealed that an intramolecular GQ structure is formed. Nondenaturing gel electrophoresis (E) visualized by UV shadow (left panel) and stained with the GQ-specific NMM dye (right panel), revealing the formation of a GQ structure at all $\mathrm{KCl}$ concentrations.

The directionality of the GQ structure formed by pre-miRNA-1229_SNP GQ was analyzed using CD spectroscopy (Figure $5 \mathrm{~B}$ ) while titrating $\mathrm{KCl}$ in the range of $0-150 \mathrm{mM}$. While the signature positive band at $\sim 265 \mathrm{~nm}$ and negative band at $\sim 240 \mathrm{~nm}$ corresponding to a parallel GQ are evident at all concentrations of $\mathrm{KCl}$, a noticeable increase in band intensity is observed upon the addition of $10 \mathrm{mM}$ $\mathrm{KCl}$, indicating the further stabilization of this $\mathrm{GQ}$ structure by $\mathrm{K}^{+}$ions and consistent with the ${ }^{1} \mathrm{H} \mathrm{NMR}$ spectroscopy results (Figure 5A) [42]. These results differ from the pre-miRNA-1229_WT GQ results (compare Figures 2B and 5B), as the GQ formed within that sequence was stable even in the absence of $\mathrm{K}^{+}$ions. Moreover, the small intensity negative band at $210 \mathrm{~nm}$ observed for pre-miRNA-1229_WT GQ (Figure 2B) is absent from the spectra of pre-miRNA-1229_SNP GQ (Figure 5B), once again suggesting the absence of loop-loop interactions within the GQ structure formed within this sequence and consistent with the ${ }^{1} \mathrm{H}$ NMR spectroscopy results. 
To determine the stability of the GQ structure formed by pre-miRNA-1229_SNP GQ, UV thermal denaturation experiments were performed at a fixed $\mathrm{KCl}$ concentration of $150 \mathrm{mM}$ and RNA concentrations in the range of 5-50 $\mu \mathrm{M}$ (Supplemental Figure S3A). At all RNA concentrations, a single hypochromic transition corresponding to GQ structure dissociation was observed which was fit (Figure 5C) using Equation (1) (Materials and Methods) to determine an average $\mathrm{T}_{\mathrm{m}}$ of $\sim 78{ }^{\circ} \mathrm{C}$ [45]. As with the wild-type pre-miRNA-1229_WT GQ sequence, the GQ melting temperatures do not depend on the RNA concentration, indicating that pre-miRNA-1229_SNP GQ forms an intramolecular GQ structure (Figure 5D) [46]. The $\mathrm{T}_{\mathrm{m}}$ values of the GQ structures formed by the wild-type and SNP truncated sequences of pre-miRNA-1229 are almost identical at $150 \mathrm{mM} \mathrm{KCl}$, suggesting that the additional stabilization observed for the GQ structure formed by pre-miRNA-1229_WT GQ originates from loop-loop interactions, potentially involving the mutated cytosine to uracil residue, interactions that are absent in pre-miRNA-1229_SNP GQ.

Finally, 20\% nondenaturing gel electrophoresis (Figure 5E) was performed at various $\mathrm{KCl}$ concentrations in the range of $0-150 \mathrm{mM}$. At each $\mathrm{KCl}$ concentration, a single main band was evident when the gel was visualized by UV shadowing (Figure 5E, left panel) [47]. This band was also present when the gel was stained by NMM (Figure 5E, right panel), indicating that it corresponds to a GQ structure [48]. An additional lower band was also present in the NMM stained gel, indicating the formation of alternative GQ structures, as was seen with pre-miRNA-1229_WT GQ (Figure 2E).

Taken together, these results show that a parallel, intramolecular GQ structure forms within pre-miRNA-1229_SNP GQ, but this structure lacks the loop-loop interactions that stabilize the GQ structure formed within the wild-type pre-miRNA-1229_WT GQ sequence.

2.4. The AD-Associated rs2291418 Mutation within the Full-Length Pre-miRNA-1229 Shifts the Equilibrium from the GQ Structure to the Extended Hairpin Structure

To determine if the GQ structure is retained in the full-length rs2291418 pre-miRNA-1229 sequence, we characterized the full 70-nucleotide sequence (named pre-miRNA-1229_SNP FL, Table 1). Similar to the full-length WT sequence, ${ }^{1} \mathrm{H}$ NMR spectroscopy experiments (Figure 6A, bottom spectrum) revealed imino proton resonances in both the GQ and Watson-Crick imino proton regions [40]. The resonances in the Watson-Crick region are well defined and sharper than those observed for pre-miRNA-1229_WT FL at all concentrations (compare Figures $3 \mathrm{~A}$ and $6 \mathrm{~A}$ ), indicating a stable hairpin structure formation. We also observed sharper resonances in the 10-12 ppm region (Figure 6A) that could originate from GG base pairs within internal loops, unpaired $G$ and $U$ residues present in the terminal loop, as well as GC Watson-Crick base pairs adjacent to internal loops of pre-miRNA-1229_SNP FL (Figure 1B) [49,50]. However, in contrast to the spectra of pre-miRNA-1229_WT FL, these resonances have a completely flat baseline even at $150 \mathrm{mM} \mathrm{KCl}$ concentrations. Only when the sample was annealed at $150 \mathrm{mM} \mathrm{KCl}$ do broad envelope resonances appear clearly in the 10-12 pm region, with the concomitant decrease in intensity of the Watson-Crick resonances, indicating that a GQ structure does not stably form in pre-miRNA-1229_SNP FL until the sample is annealed in the presence of $\mathrm{K}^{+}$ions.

To determine the directionality of the GQ structure formed in pre-miRNA-1229_SNP FL, CD spectroscopy experiments were performed at $\mathrm{KCl}$ concentrations in the range of $0-150 \mathrm{mM}$ (Figure $6 \mathrm{~B}$ ). We observed a positive band at $\sim 265 \mathrm{~nm}$, a negative band at $\sim 235 \mathrm{~nm}$, a negative band at $\sim 210 \mathrm{~nm}$, and a small negative CD between 290 and $300 \mathrm{~nm}$, consistent with the presence of a hairpin structure [42,43]. We cannot rule out the presence of a GQ structure based solely on the CD data since the signature bands of a parallel GQ structure overlap to some extent with those of an A-type hairpin structure [43]. However, we noted that the annealing of the sample in the presence of $150 \mathrm{mM} \mathrm{KCl}$ caused an increase of the intensity of the positive band at $\sim 265 \mathrm{~nm}$ with a concomitant decrease of the intensity of the negative band at $210 \mathrm{~nm}$ and a shift of the negative band from 235 to $240 \mathrm{~nm}$, indicating the formation of a stable GQ structure which coexists with the hairpin structure. These results are similar to those from the ${ }^{1} \mathrm{H}$ NMR spectroscopy experiments which show that a stable GQ structure does not form in pre-miRNA-1229_SNP FL until the sample is annealed in the presence of $\mathrm{K}^{+}$ions. 
UV thermal denaturation experiments were performed (Figure $6 \mathrm{C}$ ) at $100 \mathrm{mM} \mathrm{KCl}$ to determine the stability of the GQ structure formed within pre-miRNA-1229_SNP FL. Similar to pre-miRNA-1229_WT $\mathrm{FL}$, a hyperchromic transition corresponding to hairpin dissociation and a hypochromic transition corresponding to the GQ structure unfolding were observed (Figure $6 \mathrm{C}$, left). The hypochromic transition was fit with Equation (1) (Materials and Methods) to determine a $\mathrm{T}_{\mathrm{m}}$ of $\sim 86^{\circ} \mathrm{C}$ (Figure $6 \mathrm{C}$, right), which is comparable with the $\mathrm{T}_{\mathrm{m}}$ of the GQ structure formed by pre-miRNA-1229_WT FL [45].
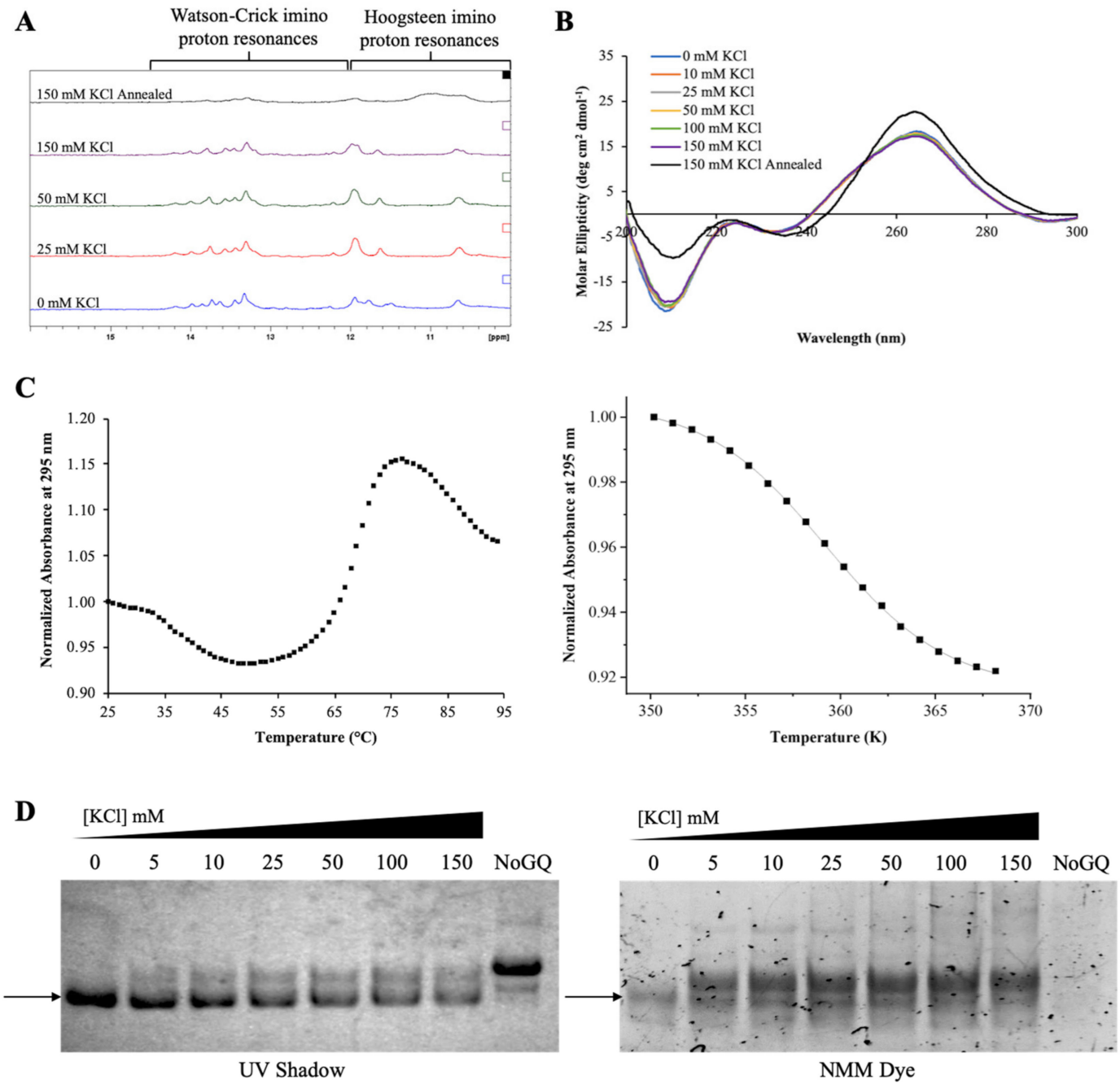

Figure 6. Biophysical characterization of the full-length pre-miR-1229_SNP FL sequence. ${ }^{1} \mathrm{H}$ NMR spectra (A) and CD spectra (B) at various $\mathrm{KCl}$ concentrations in $10 \mathrm{mM}$ cacodylic acid, $\mathrm{pH} 6.5$ reveal an equilibrium between hairpin and GQ structures after annealing the RNA in $150 \mathrm{mM} \mathrm{KCl}$. UV thermal denaturation hypochromic transition (C) at $10 \mu \mathrm{M}$ RNA in $100 \mathrm{mM} \mathrm{KCl}$ was fit using Equation (1) (Materials and Methods), to determine a $\mathrm{T}_{\mathrm{m}}$ of $\sim 86^{\circ} \mathrm{C}$. Nondenaturing gel electrophoresis (D) visualized by UV shadow (left panel) and stained with the GQ-specific NMM dye (right panel), revealing the formation of multiple GQ structures as well as a hairpin structure.

Finally, $15 \%$ nondenaturing gel electrophoresis was performed at $\mathrm{KCl}$ concentrations in the range of $0-150 \mathrm{mM}$ (Figure 6D). When the gel was visualized by UV shadowing (Figure 6D, left panel), a single main band was observed at $0 \mathrm{mM} \mathrm{KCl}$, whereas a second, upper band is clearly visible with the addition of just $5 \mathrm{mM} \mathrm{KCl}$ (compare Figure $6 \mathrm{D}$ lanes 1 and 2) [47]. As the concentration of $\mathrm{KCl}$ in the sample increased, the primary band seen at $0 \mathrm{mM} \mathrm{KCl}$ decreased in intensity, indicating an equilibrium between competing structures. When the gel was stained in NMM (Figure 6D, right panel), the main band clearly observed at $0 \mathrm{mM} \mathrm{KCl}$ by UV shadowing stains faintly, indicating that 
a GQ structure forms [48]. Since all the RNA samples were annealed prior to their loading on the gel, it is possible that the annealing could have promoted formation of the GQ structures even at $0 \mathrm{mM} \mathrm{KCl}$. Upon the addition of increasing $\mathrm{KCl}$ concentrations, the additional upper band observed when the gel was visualized by UV shadowing also stains in NMM, indicating that it originates from a GQ structure (Figure 6E, right panel). Additional fainter upper bands and a lower band are also apparent in the NMM stained gel, indicating alternative GQ structures and/or GQ stacking interactions, as was observed with pre-miRNA-1229_WT FL (Figure 3E, right panel). These results confirm that pre-miRNA-1229_SNP FL exists in equilibrium between a hairpin and GQ structures with the GQ conformations being stabilized when the RNA was annealed at $150 \mathrm{mM} \mathrm{KCl}$.

To monitor the equilibrium between the GQ and hairpin structure in pre-miRNA-1229_SNP FL in conditions that stabilize the hairpin conformation, time-dependent ${ }^{1} \mathrm{H}$ NMR spectroscopy experiments were performed in the presence of $150 \mathrm{mM} \mathrm{KCl}$ and $1 \mathrm{mM} \mathrm{MgCl}_{2}$ (Figure 7A), while the sample was incubated at $37^{\circ} \mathrm{C}$. In the presence of $\mathrm{Mg}^{2+}$ ions, there is a stabilization of the hairpin structure reflected by sharper Watson-Crick imino proton resonances between 12 and $14.5 \mathrm{pm} \mathrm{[40],} \mathrm{but} \mathrm{strikingly,} \mathrm{the} \mathrm{GQ}$ broad imino proton resonances centered around $11 \mathrm{ppm}$ decreased drastically over time (Figure 7A and overlay of spectra in Figure 7B), indicating that the equilibrium shifted towards the hairpin structure. These results are in stark contrast to the time-dependent ${ }^{1} \mathrm{H}$ NMR spectroscopy experiments for pre-miRNA-1229_WT FL (compare to Figure 4) in which the equilibrium shifted over time towards the GQ structure.

$\mathbf{A}$

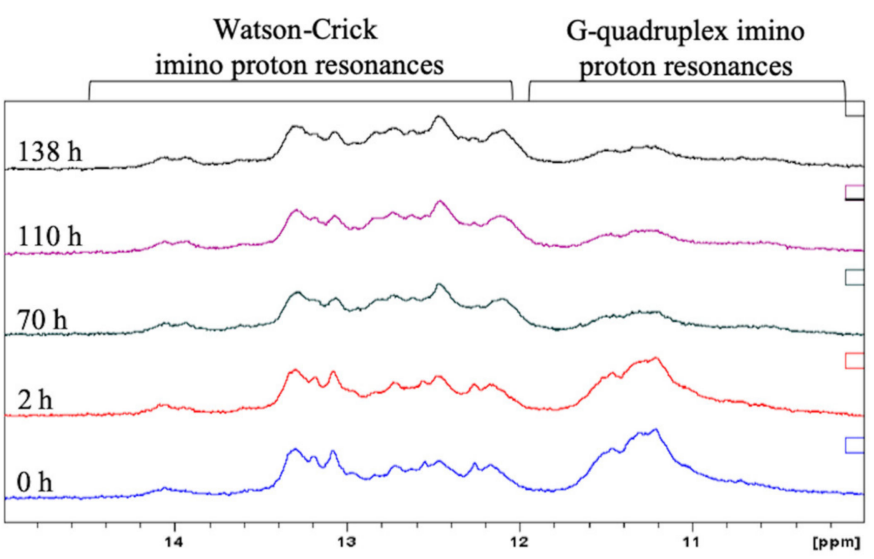

B

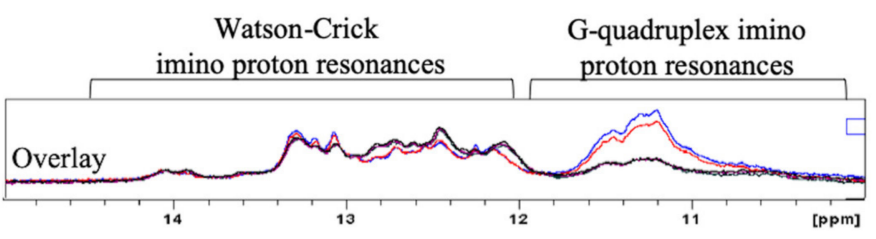

Figure 7. Time-dependent NMR spectra of full-length pre-miR-1229_SNP FL in the presence of $150 \mathrm{mM}$ $\mathrm{KCl}$ and $1 \mathrm{mM} \mathrm{MgCl}_{2}$ (A). After $138 \mathrm{~h}$, the hairpin structure is the preferred structure, as noted by the increased intensity of the Watson-Crick imino proton resonances compared to the decreased intensity of the imino proton resonances assigned to Hoogsteen base pairs in the GQ structure. An overlay of the spectra is shown in (B).

Our results indicate that while a hairpin and GQ structure coexist within the pre-miRNA-1229_SNP FL sequence, the hairpin structure is ultimately favored in the rs2291418 AD-associated variant. 


\section{Discussion}

Ghanbari et al. proposed that the observed increased levels of miRNA-1229-3p in the AD-associated rs2291418 SNP within pre-miRNA-1229 are due to the stabilization of the hairpin structure by the SNP. They predicted that the minimum free energy of the SNP hairpin was $\Delta \mathrm{G}^{\circ}=-36.10 \mathrm{kcal} / \mathrm{mol}$, whereas that of the WT was $\Delta \mathrm{G}^{\circ}=-31.90 \mathrm{kcal} / \mathrm{mol}$ [38]. However, when we folded the pre-miRNA-1229_WT FL and pre-miRNA-1229_SNP FL with the RNA Structure software (Figure 1A,C), the two hairpin structures were predicted to have free energies of $\Delta \mathrm{G}^{\circ}=-36.0 \mathrm{kcal} / \mathrm{mol}$ and $\Delta \mathrm{G}^{\circ}=-36.7 \mathrm{kcal} / \mathrm{mol}$, respectively, which differ only by $0.7 \mathrm{kcal} / \mathrm{mol}$. In this study, we showed that both the wild-type and SNP pre-miRNA-1229 sequences form GQ structures that coexist in equilibrium with the canonical extended hairpin structure and that the GQ structure is destabilized in the rs2291418 variant, possibly due to the lack of loop-loop interactions, resulting in a shift in equilibrium towards the hairpin structure.

Investigating the molecular pathways and key mechanistic steps involved in AD pathogenesis is vital for the development of therapeutic interventions for the disease. Research in the field has shifted focus to the involvement of noncoding miRNAs in $\mathrm{AD}$ due to their contributions in regulating gene expression, $A \beta$ and tau protein maintenance, inflammation, and cell death $[19,20]$. A recent study by Ke et al. suggested that miRNA-107 plays a neuroprotective role in AD progression and that its expression levels are reduced in an A $\beta$-induced AD model [52]. Furthermore, the authors of this study propose a mechanism in which the long noncoding RNA (lncRNA) NEAT1 binds to miRNA-107, leading to this downregulation. In this study, we investigated pre-miRNA-1229 due to the association of the rs2291418 variant with AD and subsequent upregulation of miRNA-1229-3p production, and we identified a GQ structure present in both the wild-type and rs2291418 variant which has the potential to be a new therapeutic target in $\mathrm{AD}[38,39]$.

However, the results of this study have implications beyond the AD context, as multiple other studies have determined that the upregulation of miRNA-1229 can be associated with various other diseases. Expression levels of miRNA-1229 were found to be correlated with increased severity of coronary artery calcification and increased tumor size in colorectal cancer [53,54]. Furthermore, miRNA-1229 overexpression has been proposed to promote cell proliferation and tumorigenicity in breast cancer [55].

This study proposes a mechanism in which the pre-miRNA-1229 equilibrium between GQ and extended hairpin structures is altered in the rs2291418 variant, potentially explaining the increased mature miRNA-1229-3p production observed in the AD-linked variant. These results warrant further investigation into how RNA structure can have downstream effects in disease pathogenesis, and ultimately how GQ structures, such as those found in pre-miRNA-1229, could be therapeutically targeted for intervention purposes in the future.

\section{Materials and Methods}

\subsection{In Vitro RNA Synthesis}

Pre-miRNA sequences (Table 1) were produced by in vitro transcription reactions using T7 RNA polymerase (synthesized in-house), following the procedure by Milligan and Uhlenbeck [56]. The DNA templates for each sequence were chemically synthesized by TriLink Biotechnologies, Inc (San Diego, CA, USA). The RNA oligonucleotides were purified by $20 \% 8 \mathrm{M}$ urea denaturing polyacrylamide gel electrophoresis (PAGE) and electrophoretic elution, followed by extensive dialysis against $10 \mathrm{mM}$ cacodylic acid, $\mathrm{pH}$ 6.5. The concentration of each oligonucleotide was measured using a NanoDrop 2000 UV-Vis spectrophotometer (ThermoFisher Scientific, Waltham, MA, USA) and their purity was checked by denaturing gel electrophoresis (data not shown).

\section{2. ${ }^{1}$ H NMR Spectroscopy}

One-dimensional (1D) proton $\left({ }^{1} \mathrm{H}\right)$ NMR spectroscopy experiments were performed on a $500 \mathrm{MHz}$ Bruker AVANCE spectrometer (Bruker Corporation, Billerica, MA, USA) at $25^{\circ} \mathrm{C}$ using Topspin 3.2 
software. Water suppression was carried out by using the Watergate pulse sequence [57]. Pre-miRNA samples with concentrations ranging from 100 to $300 \mu \mathrm{M}$ were prepared in a volume of $250 \mu \mathrm{L} 10 \mathrm{mM}$ cacodylic acid, $\mathrm{pH}$ 6.5, in a 90:10 ratio of $\mathrm{H}_{2} \mathrm{O}: \mathrm{D}_{2} \mathrm{O}$. GQ formation was observed by titrating increasing concentrations of $\mathrm{KCl}$ from a $2 \mathrm{M}$ stock solution to each sample. The samples containing $150 \mathrm{mM} \mathrm{KCl}$ were also annealed by boiling at $95^{\circ} \mathrm{C}$ for $5 \mathrm{~min}$ and cooling on the bench for $15 \mathrm{~min}$. Time-dependent NMR spectroscopy studies were conducted following the addition of $1 \mathrm{mM} \mathrm{MgCl} 2$ to each sample and incubating at $37^{\circ} \mathrm{C}$, while acquiring spectra over time.

\subsection{Circular Dichroism Spectroscopy}

Circular dichroism (CD) spectroscopy experiments were recorded on a Jasco J-810 spectropolarimeter (JASCO, Easton, MD, USA) at $25^{\circ} \mathrm{C}$. Pre-miRNA samples were prepared in $10 \mathrm{mM}$ cacodylic acid, $\mathrm{pH} 6.5$ to a final RNA concentration of $10 \mu \mathrm{M}$ in a volume of $200 \mu \mathrm{L}$. GQ formation was monitored by titrating increasing amounts of $\mathrm{KCl}$ from a $2 \mathrm{M}$ stock solution to each sample and subsequently annealing the sample at $95^{\circ} \mathrm{C}$ for 5 min once a final $\mathrm{KCl}$ concentration of $150 \mathrm{mM}$ was reached. Spectra were measured between 200 and $300 \mathrm{~nm}$ and corrected for solvent contributions. Each spectrum was scanned seven times with a $1 \mathrm{~s}$ response time and a $2 \mathrm{~nm}$ bandwidth. CD spectroscopy experiments were performed in duplicate $(n=2)$ for each RNA.

\subsection{UV Spectroscopy Thermal Denaturation}

Thermal denaturation experiments were conducted using a Varian Cary 3E UV/Vis spectrophotometer (Agilent, Santa Clara, CA, USA) equipped with a Peltier cell. RNA samples were annealed in $10 \mathrm{mM}$ cacodylic acid, pH 6.5, containing 100-150 mM KCl. Samples were heated from 25 to $95{ }^{\circ} \mathrm{C}$ at a rate of $0.2^{\circ} \mathrm{C} \mathrm{min}-1$, recording points every $1{ }^{\circ} \mathrm{C}$ at $295 \mathrm{~nm}$, a wavelength previously identified to be sensitive to G-quadruplex dissociation [44]. To determine if the structures fold into intermolecular or intramolecular conformations, the melting temperatures of the G-quadruplex structures were determined at various RNA concentrations. The transitions of each dissociation were identified and fit with Equation (1) [45]:

$$
A(T)=\frac{A_{U}+A_{F} e^{\frac{-\Delta H^{\circ}}{R T}} e^{\frac{\Delta S^{\circ}}{R}}}{e^{\frac{-\Delta H^{\circ}}{R T}} e^{\frac{\Delta S^{\circ}}{R}}+1}
$$

where $A_{U}$ and $A_{F}$ represent the absorbance of the unfolded and native GQ RNA, respectively, and $R$ is the universal gas constant.

\subsection{Nondenaturing Polyacrylamide Gel Electrophoresis}

RNA samples were prepared with varying $\mathrm{KCl}$ concentrations and a constant RNA concentration of $10 \mu \mathrm{M}$, followed by heating for $5 \mathrm{~min}$ at $95^{\circ} \mathrm{C}$ and slow cooling to room temperature. Samples were run on $15 \%$ or $20 \%$ acrylamide gels and visualized using an AlphaImager (ProteinSimple, San Jose, CA, USA) by UV shadowing at $254 \mathrm{~nm}$ [47]. Gels were subsequently stained in $N$-methyl mesoporphyrin IX (NMM), a GQ-specific fluorescent probe, and visualized to determine if the GQ structure forms at various concentrations of $\mathrm{KCl}$ [48]. Gel electrophoresis experiments were performed in triplicate $(n=3)$ for each RNA.

\section{Conclusions}

Collectively, the biophysical characterization experiments performed in this study determined that pre-miRNA-1229 forms a GQ structure which coexists in equilibrium with an extended hairpin structure. This study adds to the growing number of G-rich pre-miRNA sequences shown to form GQ structures that could interfere with their processing by Dicer and the production of mature miRNA, ultimately providing a fine-tuning mechanism for regulating translation. Furthermore, we show that while in the WT pre-miRNA-1229 the GQ structure is preferred, in the AD-associated rs2291418 pre-miRNA-1229 variant the equilibrium is shifted towards the extended hairpin structure which 
can be processed by Dicer, possibly explaining the observed increased production of the mature miRNA-1229-3p in this variant. The results from this study elucidate a potential role of RNA secondary structure equilibrium in the $\mathrm{AD}$ pathogenesis and warrant further investigation into how GQ structures could be therapeutically targeted in the future.

Supplementary Materials: Supplementary materials can be found at http://www.mdpi.com/1422-0067/21/3/767/s1.

Author Contributions: Conceptualization, M.R.M. and J.A.I.; Methodology, M.R.M. and J.A.I.; Investigation, J.A.I., M.L.T. and K.B.M.; Validation, J.A.I., M.L.T. and K.B.M.; Formal analysis, M.R.M. and J.A.I.; Data curation, J.A.I.; Writing—Original draft preparation, J.A.I.; Writing — Review and editing, M.R.M.; Supervision, M.R.M.; Project administration, M.R.M.; Funding acquisition, M.R.M. All authors have read and agreed to the published version of the manuscript.

Funding: This research was supported by the N.I.H. grant 9 R15 GM127307-04 to M.R.M, NSF/S-STEM: DUE-1259941 and NSF/MRI: CHE-1726824.

Acknowledgments: We would like to thank Kendy A. Pellegrene for the design of the graphical abstract.

Conflicts of Interest: The authors declare no conflict of interest.

\section{Abbreviations}

$\begin{array}{ll}\text { AD } & \text { Alzheimer's disease } \\ \text { A } \beta & \beta \text {-amyloid } \\ \text { SORL1 } & \text { Sortilin-related receptor } \\ \text { miRNA } & \text { microRNA } \\ \text { nt } & \text { nucleotide } \\ \text { RISC } & \text { RNA-induced silencing complex } \\ \text { GQ } & \text { G-quadruplex } \\ \text { SNP } & \text { Single nucleotide polymorphism } \\ \text { NMR } & \text { Nuclear magnetic resonance } \\ \text { CD } & \text { Circular dichroism } \\ \text { UV } & \text { Ultraviolet } \\ T_{m} & \text { Melting temperature } \\ \text { NMM } & \text { N-methyl mesoporphyrin IX }\end{array}$

\section{References}

1. Hebert, L.E.; Weuve, J.; Scherr, P.A.; Evans, D.A. Alzheimer disease in the United States (2010-2050) estimated using the 2010 census. Neurology 2013, 80, 1778-1783. [CrossRef]

2. Förstl, H.; Kurz, A. Clinical features of Alzheimer's disease. Eur. Arch. Psychiatry Clin. Neurosci. 1999, 249, 288-290. [CrossRef] [PubMed]

3. Barker, W.W.; Luis, C.A.; Kashuba, A.; Luis, M.; Harwood, D.G.; Loewenstein, D.; Waters, C.; Jimison, P.; Shepherd, E.; Sevush, S.; et al. Relative frequencies of Alzheimer's disease, Lewy body, vascular and frontotemporal dementia, and hippocampal sclerosis in the state of Florida brain bank. Alzheimer Dis. Assoc. Disord. 2002, 16, 203-212. [CrossRef] [PubMed]

4. Wilson, R.S.; Segawa, E.; Boyle, P.A.; Anagnos, S.E.; Hizel, L.P.; Bennett, D.A. The natural history of cognitive decline in Alzheimer's disease. Psychol. Aging 2012, 27, 1008-1017. [CrossRef] [PubMed]

5. Selkoe, D.J. Alzheimer's disease: Genes, proteins, and therapy. Physiol. Rev. 2001, 81, 741-766. [CrossRef]

6. Glenner, G.G.; Wong, C.W. Alzheimer's disease: Initial report of the purification and characterization of a novel cerebrovascular amyloid protein. Biochem. Biophys. Res. 1984, 120, 885-890. [CrossRef]

7. Iwatsubo, T.; Odaka, A.; Suzuki, N.; Mizusawa, H.; Nukina, N.; Ihara, Y. Visualization of A $\beta 42$ and A $\beta 40$ in senile plaques with end-specific $A \beta$ monoclonals: evidence that an initially deposited species is $A \beta 42$. Neuron 1994, 13, 45-53. [CrossRef]

8. Hardy, J.A.; Higgins, G.A. Alzheimer's disease: The amyloid cascade hypothesis. Science 1992, 256, 184-185. [CrossRef] 
9. Citron, M.; Oltersdorf, T.; Haass, C.; McConlogue, L.; Hung, A.Y.; Seubert, P.; Vigo-Pelfrey, C.; Lieberburg, I.; Selkoe, D.J. Mutation of the $\beta$-amyloid precursor protein in familial Alzheimer's disease increases $\beta$-protein production. Nature 1992, 360, 672-674. [CrossRef]

10. Suzuki, N.; Cheung, T.T.; Cai, X.; Odaka, A.; Otvos, L. Jr.; Eckman, C.; Golde, T.E.; Younkin, S.G. An increased percentage of long amyloid $\beta$ protein secreted by familial amyloid $\beta$ protein precursor $\left(\beta \mathrm{APP}_{717}\right)$ mutants. Science 1994, 264, 1336-1340. [CrossRef]

11. Strittmatter, W.J.; Saunders, A.M.; Schmechel, D.; Pericak-Vance, M.; Enghild, J.; Salvesen, G.S.; Roses, A.D. Apolipoprotein E: high-avidity binding to $\beta$-amyloid and increased frequency of type 4 allele in late-onset familial Alzheimer disease. Proc. Natl. Acad. Sci. USA 1993, 90, 1977-1981. [CrossRef] [PubMed]

12. Li, Y.; Grupe, A.; Rowland, C.; Nowotny, P.; Kauwe, J.S.K.; Smemo, S.; Hinrichs, A.; Tacey, K.; Toombs, T.A.; Kwok, S.; et al. DAPK1 variants are associated with Alzheimer's disease and allele-specific expression. Human Mol. Genet. 2006, 15, 2560-2568. [CrossRef] [PubMed]

13. Li, K.; Liu, S.; Yao, S.; Wang, B.; Dai, D.; Yao, L. Interaction between interleukin-8 and methylenetetrahydrofolate reductase genes modulates Alzheimer's disease risk. Dement. Geriatr. Cogn. Disord. 2009, 27, $286-291$. [CrossRef] [PubMed]

14. Van Rensburg, S.J.; Carstens, M.E.; Potocnik, F.C.; Aucamp, A.K.; Taljaard, J.J. Increased frequency of the transferrin C2 subtype in Alzheimer's disease. Neuroreport 1993, 4, 1269-1271. [CrossRef] [PubMed]

15. Ciarlo, E.; Massone, S.; Penna, I.; Nizzari, M.; Gigoni, A.; Dieci, G.; Russo, C.; Florio, T.; Cancedda, R.; Pagano, A. An intronic ncRNA-dependent regulation of SORL1 expression affecting A $\beta$ formation is upregulated in post-mortem Alzheimer's disease brain samples. Dis. Models Mech. 2013, 6, 424-433. [CrossRef] [PubMed]

16. Jacobsen, L.; Madsen, P.; Moestrup, S.K.; Lund, A.H.; Tommerup, N.; Nykjær, A.; Sottrup-Jensen, L.; Gliemann, J.; Petersen, C.M. Molecular characterization of a novel human hybrid-type receptor that binds the $\alpha_{2}$-macroglobulin receptor-associated protein. J. Biol. Chem. 1996, 271, 31379-31383. [CrossRef] [PubMed]

17. Motoi, Y.; Aizawa, T.; Haga, S.; Nakamura, S.; Namba, Y.; Ikeda, K. Neuronal localization of a novel mosaic apolipoprotein E receptor, LR11, in rat and human brain. Brais Res. 1999, 833, 209-215. [CrossRef]

18. Rogaeva, E.; Meng, Y.; Lee, J.H.; Gu, Y.; Kawarai, T.; Zou, F.; Katayama, T.; Baldwin, C.T.; Cheng, R.; Hasegawa, H.; et al. The neuronal sortilin-related receptor SORL1 is genetically associated with Alzheimer's disease. Nat. Genet. 2007, 39, 168-177. [CrossRef]

19. Tan, L.; Yu, J.; Hu, N.; Tan, L. Non-coding RNAs in Alzheimer's disease. Mol. Neurobiol. 2013, 47, $382-393$. [CrossRef]

20. Idda, M.L.; Munk, R.; Abdelmohsen, K.; Gorospe, M. Noncoding RNAs in Alzheimer's disease. WIRES RNA 2017, 9, e1463. [CrossRef]

21. Bartel, D.P. MicroRNAs: genomics, biogenesis, mechanism, and function. Cell 2004, 116, 281-297. [CrossRef]

22. Lee, Y.; Kim, M.; Han, J.; Yeom, K.; Lee, S.; Baek, S.H.; Kim, V.N. MicroRNA genes are transcribed by RNA polymerase II. EMBO J. 2004, 23, 4051-4060. [CrossRef] [PubMed]

23. Lee, Y.; Ahn, C.; Han, J.; Choi, H.; Kim, J.; Yim, J.; Lee, J.; Provost, P.; Rådmark, O.; Kim, S.; et al. The nuclear RNase III Drosha initiates microRNA processing. Nature 2003, 425, 415-419. [CrossRef] [PubMed]

24. Han, J.; Lee, Y.; Yeom, K.; Kim, Y.; Jin, H.; Kim, V.N. The Drosha-DGCR8 complex in primary microRNA processing. Genes Dev. 2004, 18, 3016-3027. [CrossRef] [PubMed]

25. Yi, R.; Qin, Y.; Macara, I.G.; Cullen, B.R. Exportin-5 mediates the nuclear export of pre-microRNAs and short hairpin RNAs. Genes Dev. 2003, 17, 3011-3016. [CrossRef] [PubMed]

26. Bernstein, E.; Caudy, A.A.; Hammond, S.M.; Hannon, G.J. Role for a bidentate ribonuclease in the initiation step of RNA interference. Nature 2001, 409, 363-366. [CrossRef]

27. Hutvágner, G.; McLachlan, J.; Pasquinelli, A.E.; Bálint, É.; Tuschl, T.; Zamore, P.D. A cellular function for the RNA-interference enzyme Dicer in the maturation of the let-7 small temporal RNA. Science 2001, 293, 834-838. [CrossRef]

28. Chendrimada, T.P.; Gregory, R.I.; Kumaraswamy, E.; Norman, J.; Cooch, N.; Nishikura, K.; Shiekhattar, R. TRBP recruits the Dicer complex to Ago2 for microRNA processing and gene silencing. Nature 2005, 436, 740-744. [CrossRef]

29. Yoda, M.; Kawamata, T.; Paroo, Z.; Ye, X.; Iwasaki, S.; Liu, Q.; Tomari, Y. ATP-dependent human RISC assembly pathways. Nat. Struct. Mol. Biol. 2010, 17, 17-23. [CrossRef] 
30. Khvorova, A.; Reynolds, A.; Jayasena, S.D. Functional siRNAs and miRNAs exhibit strand bias. Cell 2003, 115, 209-216. [CrossRef]

31. Amakiri, N.; Kubosumi, A.; Tran, J.; Reddy, P.H. Amyloid beta and microRNAs in Alzheimer's disease. Front. Neurosci. 2019, 13, 430. [CrossRef] [PubMed]

32. Brás, A.; Rodrigues, A.S.; Gomes, B.; Rueff, J. Down syndrome and microRNAs. Biomed. Rep. 2018, 8, 11-16. [PubMed]

33. Paul, P.; Chakraborty, A.; Sarkar, D.; Langthasa, M.; Rahman, M.; Bari, M.; Singha, R.K.S.; Malakar, A.K.; Chakraborty, S. Interplay between miRNAs and human disease. J. Cell. Physiol. 2018, 233, 2007-2018. [CrossRef] [PubMed]

34. Pandey, S.; Agarwala, P.; Jayaraj, G.G.; Gargallo, R.; Maiti, S. The RNA stem-loop to G-quadruplex equilibrium controls mature microRNA production inside the cell. Biochemistry 2015, 54, 7067-7078. [CrossRef]

35. Arachchilage, G.M.; Dassanayake, A.C.; Basu, S. A potassium ion-dependent RNA structural switch regulates pre-miRNA 92b maturation. Chem. Biol. 2015, 22, 262-272.

36. Williamson, J.R.; Raghuraman, M.K.; Cech, T.R. Monovalent cation-induced structure of telomeric DNA: The G-quartet model. Cell 1989, 59, 871-880. [CrossRef]

37. Williamson, J.R. G-quartet structures in telomeric DNA. Annu. Rev. Biophys. Biomol. Struct. 1994, 23, 703-730. [CrossRef]

38. Ghanbari, M.; Ikram, M.A.; de Looper, H.W.J.; Hofman, A.; Erkeland, S.J.; Franco, O.H.; Dehghan, A. Genome-wide identification of microRNA-related variants associated with risk of Alzheimer's disease. Sci. Rep. 2016, 6, 28387. [CrossRef]

39. Balasubramanian, S.; Neidle, S. G-quadruplex nucleic acids as therapeutic targets. Curr. Opin. Chem. Biol. 2009, 13, 345-353. [CrossRef]

40. Fürtig, B.; Richter, C.; Wöhnert, J.; Schwalbe, H. NMR spectroscopy of RNA. ChemBioChem 2003, 4, 936-962. [CrossRef]

41. Joachimi, A.; Benz, A.; Hartig, J.S. A comparison of DNA and RNA quadruplex structures and stabilities. Bioorg. Med. Chem. 2009, 19, 6811-6815. [CrossRef] [PubMed]

42. Miyoshi, D.; Nakao, A.; Sugimoto, N. Structural transition from antiparallel to parallel G-quadruplex of $\mathrm{d}\left(\mathrm{G}_{4} \mathrm{~T}_{4} \mathrm{G}_{4}\right)$ induced by $\mathrm{Ca}^{2+}$. Nucleic Acids Res. 2003, 31, 1156-1163. [CrossRef] [PubMed]

43. Ranjbar, B.; Gill, P. Circular dichroism techniques: biomolecular and nanostructural analyses-A review. Chem. Biol. Drug Des. 2009, 74, 101-120. [CrossRef] [PubMed]

44. Mergny, J.L.; Phan, A.T.; Lacroix, L. Following G-quartet formation by UV-spectroscopy. FEBS Lett. 1998, 435, 74-78. [CrossRef]

45. Menon, L.; Mader, S.A.; Mihailescu, M. Fragile X mental retardation protein interactions with the microtubule associated protein 1B RNA. RNA 2008, 14, 1644-1655. [CrossRef]

46. Hardin, C.C.; Perry, A.G.; White, K. Thermodynamic and kinetic characterization of the dissociation and assembly of quadruplex nucleic acids. Biopolymers 2001, 56, 147-194. [CrossRef]

47. Hendry, P.; Hannan, G. Detection and quantitation of unlabeled nucleic acids in polyacrylamide gels. BioTechniques 1996, 20, 258-264. [CrossRef]

48. Arthanari, H.; Basu, S.; Kawano, T.L.; Bolton, P.H. Fluorescent dyes specific for quadruplex DNA. Nucleic Acids Res. 1998, 26, 3724-3728. [CrossRef]

49. Glemarec, C.; Kufel, J.; Földesi, A.; Maltseva, T.; Sandström, A.; Kirsebom, L.A.; Chattopadhyaya, J. The NMR structure of 31mer RNA domain of Escherichia coli RNAse P RNA using its non-uniformly deuterium labelled counterpart [the 'NMR-window' concept]. Nucleic Acids Res. 1996, 24, 2022-2035. [CrossRef]

50. Shankar, N.; Kennedy, S.D.; Chen, G.; Krugh, T.R.; Turner, D.H. The NMR structure of an internal loop from $23 \mathrm{~S}$ ribosomal RNA differs from its structure in crystals of $50 \mathrm{~S}$ ribosomal subunits. Biochemistry 2006, 45, 11776-11789. [CrossRef]

51. Serra, M.J.; Baird, J.D.; Dale, T.; Fey, B.L.; Retatagos, K.; Westhof, E. Effects of magnesium ions on the stabilization of RNA oligomers of defined structures. RNA 2002, 8, 307-323. [CrossRef] [PubMed]

52. Ke, S.; Yang, Z.; Yang, F.; Wang, X.; Tan, J.; Liao, B. Long noncoding RNA NEAT1 aggravates A $\beta$-induced neuronal damage by targeting miR-107 in Alzheimer's disease. Yonsei Med. J. 2019, 60, 640-650. [CrossRef] [PubMed] 
53. Liu, W.; Ling, S.; Sun, W.; Liu, T.; Li, Y.; Zhong, G.; Zhao, D.; Zhang, P.; Song, J.; Jin, X.; et al. Circulating microRNAs correlated with the level of coronary artery calcification in symptomatic patients. Sci. Rep. 2015, 5, 16099. [CrossRef] [PubMed]

54. Hu, H.; Yu, C.; Zhang, H.; Zhang, S.; Yu, W.; Yang, Y.; Chen, Q. Exosomal miR-1229 derived from colorectal cancer cells promotes angiogenesis by targeting HIPK2. Int. J. Biol. Macromol. 2019, 132, 470-477. [CrossRef] [PubMed]

55. Tan, Z.; Zheng, H.; Liu, X.; Zhang, W.; Zhu, J.; Wu, G.; Cao, L.; Song, J.; Wu, S.; Song, L. MicroRNA-1229 overexpression promotes cell proliferation and tumorigenicity and activates $\mathrm{Wnt} / \beta$-catenin signaling in breast cancer. Oncotarget 2016, 7, 24076-24087. [CrossRef] [PubMed]

56. Milligan, J.F.; Uhlenbeck, O.C. Synthesis of small RNAs using T7 RNA polymerase. Methods Enzymol. 1989, 180, 51-62. [PubMed]

57. Piotto, M.; Saudek, V.; Sklenár, V. Gradient-tailored excitation for single-quantum NMR spectroscopy of aqueous solutions. J. Biomol. NMR 1992, 2, 661-665. [CrossRef]

(C) 2020 by the authors. Licensee MDPI, Basel, Switzerland. This article is an open access article distributed under the terms and conditions of the Creative Commons Attribution (CC BY) license (http://creativecommons.org/licenses/by/4.0/). 